مجلة كلية التربية، جامعة الأزهر، العدد: (180، الجزء الثاني) أكتوبر لسنة 2018م

\title{
Brain Dominance and the Use of Technology for Learning Purposes in College Students: \\ A Cross-Cultural Study
}

\begin{abstract}
:
The current study aimed to examine the relation between brain dominance and the use of technology for learning purposes across three countries. Participants included 634 male and female students enrolled in universities in Saudi Arabia, Egypt, and Algeria, selected through stratified cluster sampling. Participants completed a series of questionnaires assessing brain dominance and the use of technology for learning purposes. Analysis demonstrated that females reported greater QC and QD dominance than men. Statistically significant positive relationships between brain dominance and the use of technology for learning purposes were also found. The brain dominance variables accounted for $79 \%$ of the variance in using technology for learning purposes. Adjusting for the other brain dominance predictor variables, only QC (positively) and QD (inversely) were significant. Results may inform the development of special education programs among technology users to enhance their learning potential.
\end{abstract}

Keywords: Brain Dominance; Age Group, Gender; Technology of Learning.

\section{Introduction:}

Modern technology has affected the learning methods used by the current digital generation. As a result, traditional methods of learning that are often still used within educational institutions may be in stark contrast to the methods utilized by students in the outside world. A fundamental transformation of the educational system to adapt to these technology-based learning methods is inevitable; hence, educators must strive to diminish the disparity between these learning modalities and seek to utilize the power of technology to facilitate student success (Klopfer, Osterweil, Groff, \& Haas, 2009).

The ability of youth to increasingly use and incorporate technology into multiple aspects of their daily life has led them to adopt certain learning preferences and expectations (Baird \& Fisher, 2005). During the 1980 s, there was a radical shift in learning methods to more efficiently and effectively build knowledge (Boekaerts \& Minnaert, 2006), moving from a teacherfocused method of disseminating information to a student-focused approach. Emphasis on the student has led to an interest in structural models of learning (Boyle, Duffy, \& Dunleavy, 2003; 
Driscoll \& Driscoll, 2005; Boekaerts \& Minnaert, 2006), and, combined with advancements in personal technology, to the possibility of using technology to support self-directed learning (Van Harmelen, 2008). For instance, the use of wikis may allow learning groups to work together to construct and form common systems of knowledge, both within and outside the classroom. Groups can also form wikis that reflect certain cultural and social views. Additionally, blogs allow individual learners to develop learning activities for their own development, as well as build learning communities. Thus, different technology modalities may be used in educational settings to enable learners to construct their own system of learning. However, as technology is increasingly used to aid learning, it is important to identify individual difference characteristics that may influence the use of technology for learning. One such characteristic that warrants investigation is brain hemispheric dominance.

\section{Brain Hemispheric Dominance:}

Although individuals use both the left and right hemispheres of their brains in most situations (Roalf et al., 2014; Thompson et al., 2015), there are significant functional differences between the two hemispheres. The left hemisphere is largely concerned with operating (oral and written) verbal information (e.g. analyzing, organizing, and abstracting); it is also responsible for symbolic reasoning more generally and logic-based decision making, in addition to dominating mathematics, colors, tools, scientific skills, and body parts. Left-hemisphere-dominant individuals have the ability to explain themselves well (Shaw et al., 2016); they analyze information linearly, starting with individual pieces of information and compiling them in a logical manner and rearranging them until a result is obtained. They process information consecutively and tend to work with daily plans and schedules; they continue performing subtasks until the main, superordinate task is completed (Rodriguez \& Rafael, 1994). Given these functions, the left hemisphere is considered to be the verbal, analytical, logical, and realistic hemisphere (Kathleen \& Eliassen, 1998).

The right hemisphere, on the other hand, dominates nonverbal functions, such as intuition, emotion, creativity and imagination. It has a larger role in recognizing and analyzing three-dimensional works, especially through visual perception or visuospatial abilities. It also assists in the processing of information, images, and music, as well as responds to emotional stimuli; therefore, it is considered to be the nonverbal, intuitive, sensory, and emotive hemisphere (Penfield \& Roberts, 2014). The right hemisphere works holistically in information processing; it 
مجلة كلية التربية، جامعة الأزهر، العدد: (180، الجزء الثاني) أكتوبر لسنة 2018م

starts with the whole and then moves into the parts (Webb \& Adler, 2016). Although each hemisphere has its own characteristics and some functions depend more on a certain hemisphere than the other, ultimately most functions rely on both hemispheres (Kathleen \& Eliassen, 1998; Springer \& Deutsch, 1998).

Brain hemispheric dominance (referred to as brain dominance from this point forward) is considered a broad term and, although definitions of this construct vary throughout the literature (Liu \& Graf, 2009; Wu \& Alrabah, 2009), researchers are in agreement that brain dominance can be broadly defined as the way in which an individual typically processes or understands information (Slack \& Norwich, 2007; Zacharis, 2011). As such, the study of brain dominance may aid in identifying the specific strategies for learning that best fit individual learning styles (Goorha \& Mohan, 2009). Four preferences (or learning styles) have been proposed, based on the dominance of specific quadrants of the brain. According to Herrmann (1995), these learning preferences are: the Upper Left Brain (quadrant A [QA]); the Lower Left Brain (quadrant B [QB]); the Lower Right Brain (quadrant $C[Q C]$ ), and the Upper Right Brain (quadrant D [QD]). QA dominant individuals produce principle and mathematical formulas, discover the most efficient way to accomplish tasks or solve problems to preserve effort, and calculate possibilities. QA dominant individuals rely on facts and logic to solve problems, developing hypotheses and avoiding emotions (Herrmann, 1995). QB dominant individuals, however, establish rules based on what has worked in the past. QB dominant individuals may also be resistant to change. Relative to QA, QB is considered the action-oriented quadrant. $Q B$ dominant individuals ensure tasks are done on time and correctly, focusing on only one task at a time (Al Ghraibeh, 2013).

QC dominant individuals take in experience. They are preoccupied with facts associated with emotional trends, recognizing mood changes as soon as they happen, responding to those changes calmly. Experience is viewed as a fact and there is little regard for logic (Al Ghraibeh, 2013). Emotions and spirituality provide QC dominant individuals with a sense of belonging to the world. QC dominant individuals are sentimental, consensual, and seek harmony (Al Ghraibeh, 2013). Similar to QB dominant individuals, QC dominant individuals are engaged with the past; thus, as QC dominance expands, QB dominance is diminished. Finally, QD dominant individuals thrive on the excitement of new ideas, possibilities, and questions. QD dominant individuals are imaginative, artistic, and can be confusing. They often are unable to understand others or themselves. They tend to 
not work well with others due to their inability to set dates for project delivery and work completion (Herrmann \& Herrmann, 2015). The creativity associated with QD dominance functions with the support of the other quadrants (Herrmann, 1995).

\section{Brain Dominance and the Use of Technology to Learn:}

The use of technology for learning purposes, or the use of electronic learning means such as mobile devices, internet, and/or computers, to access available networks as a learning strategy and method (Stephen, 2012), is a flexible mechanism that can be adjusted in several ways depending on an individual's learning needs and interests. The method that students use to enhance their own learning will be the method that suits their brain dominance. Depending on an individual's brain dominance, learning and education through technology may emphasize indoctrination, logic, creativity, initiative, flexibility, emotiveness, visualization, and free-thinking during the learning process - all of which are considered functions of the different brain quadrants previously discussed (Lieberman, 2012).

There is evidence that the use of technology is associated with brain activation. For example, while conducting a search of the Web, volunteers with prior Internet experience registered a twofold increase in brain activation compared to those with little Internet experience (Champeau, 2008). However, research examining the connection between brain dominance and technology use for learning is in its infancy, and as a result, there is currently limited evidence for the specific brain locations activated when technology is used. From the studies that have been conducted in this area, there is evidence to suggest the influence of the sensory cerebral cortex (right brain: C Quadrant) in processing various technology (Anderson, Bechara, Damasio, Tranel, \& Damasio, 1999). Similarly, an increase in grey matter volume in many regions of the brain that play a role in learning, specifically in the prefrontal cortex, has also been found (Miller, 2011). Four different brain regions (fronto-temporal, frontoparietal, fronto-amygdala, and the insular cortex networks) have been associated with the processing of learning issues (Lahnakoski et al., 2012). Additionally, use of technology for learning purposes has been correlated with three learning regions; specifically, the left amygdala, the right amygdala, and the temporal cortex (Von Der Heide, Vyas, \& Olson, 2014). Furthermore, the prefrontal cortex has been shown to play a vital role in comprehension ( $\mathrm{Li}$, Mai, \& Liu, 2014).

Given the dearth of information on the relation between brain dominance and the use of technology in learning, as well as the implication of this relation for updating and developing new 
teaching methods, the primary aim of the present study was to examine the relation between brain dominance and the use of technology for learning. A secondary aim of this study was to examine age (groups of 17-21, 22-26, and 27+ years of age), nationality (Saudi, Egyptian, and Algerian), and gender (males, females) as moderators of the relation between brain dominance and the use of technology.

\section{Hypotheses:}

H1: There is a significant relationship between brain dominance and use of technology for learning purposes. Specifically, the QC; QD quadrants should be associated with greater preference of using technology for learning purposes.

\section{Methods:}

\section{Study Sample:}

Stratified random cluster sampling was implemented in selected universities in Saudi Arabia, Egypt, and Algeria, to obtain a sample of 634 students. Of these, 337 were male and 297 were female, en rolled in their respective universities. The sample age groups were categorized into three levels (17-21, 22-26, and $27+$ years of age). The distribution of participants across these groups as a function of gender and country of residence is presented in Table 1.

Table1: Distribution of the Sample Based on the Country of Residence

\begin{tabular}{|c|c|c|c|c|c|}
\hline \multirow[t]{2}{*}{ Country } & \multirow[t]{2}{*}{ Gender } & \multicolumn{3}{|c|}{ Age } & \multirow{2}{*}{ Overall } \\
\hline & & 17-21 & $22-26$ & $27+$ & \\
\hline \multirow{3}{*}{ Saudi Arabia } & $\overline{\mathbf{M}}$ & 13 & 79 & 43 & 135 \\
\hline & $\mathbf{F}$ & 26 & 55 & 17 & 98 \\
\hline & Total & 39 & 134 & 60 & 233 \\
\hline \multirow{3}{*}{ Egypt } & $\overline{\mathbf{M}}$ & 34 & 35 & 35 & 104 \\
\hline & $\mathbf{F}$ & 31 & 36 & 31 & 98 \\
\hline & Total & 65 & 71 & 66 & 202 \\
\hline \multirow[t]{3}{*}{ Algeria } & $\overline{\mathbf{M}}$ & $\overline{14}$ & $\overline{77}$ & $\overline{7}$ & 98 \\
\hline & $\mathbf{F}$ & 7 & 88 & 6 & 101 \\
\hline & Total & 21 & 165 & 13 & 199 \\
\hline Overall & & 125 & 370 & 139 & 634 \\
\hline
\end{tabular}


مجلة كلية التربية، جامعة الأزهر، العدد: (180، الجزء الثاني) أكتوبر لسنة 2018م

\section{Measures:}

A survey instrument, adapted with permission from the survey of student usage of technology conducted by Kennedy et al. (2007), was used to collect participant demographic data. This instrument collected such information as age, gender, and nationality. The survey also used a series of Likert scale questions to solicit participant's usage of technology for learning

Use of Technology for Learning Purposes Scale. The scale was adapted from Kennedy, et al. (2007) and translated into Arabic (using a back translation procedure), with the final version including 20 items measuring the use of technology for learning purposes. We used these steps to translate the scale: 1) The scale was presented to a professor in psychology and another in learning techniques (both of whom have expertise in Arabic and English), and they were instructed to translate the scale from English to Arabic; 2) The scale was presented to two other language proficient professors, one of them with expertise in psychology and another specialized in teaching techniques, and they were instructed to translate the scale from Arabic to English!

3) The consistency of translation for both languages was verified;

4) The scale items were finalized after feedback was received from this process.

Subjects responded to each item according to their level of certainty using a 5-point Likert scale. Example measure items included, "Design and build web pages as part of your course (e.g., using Dreamweaver, FrontPage)?"; "Create and present multimedia shows as part of your course requirements (e.g., PowerPoint)?" The internal consistency of the scale was acceptable (Cronbach's $\alpha=0.91)$. Responses were summed and the following scale was used to classify results: From (1-1.80) "very low use of technology," (1.81-2.60) "low use of technology," (2.61-3.40) "moderate use of technology," (3.41-4.20) high use of technology, and (4.21-5) "very high use of technology (Kennedy, et al.,2007).

Brain Dominance. The brain dominance test was constructed based on Herrmann's (1995) Brain Dominance Instrument and included 120 items. The Herrmann (1995) instrument was revised and developed by She (2005) into the Chinese language. In this iteration of the testing instrument, the total number of items was reduced to 60, which described a series of learning activities preferred by students. Each brain quadrant refers to a learning style (i.e., QA, QB, QC and QD), and is measured by 15 items according to Herrmann (1995) and She (2005). The test was translated into Arabic by Al-Nawafleh (2008). Previous studies (Al Gharaibeh, 2013; Al Gharaibeh, 2015) ensured the validity and 
reliability of the test. The number of items responded to within each quarter of the brain was calculated. The internal consistencies of each brain dominance subscale were acceptable (QA Cronbach's $\alpha=.77$, QB Cronbach's $\alpha=.80$, QC Cronbach's $\alpha=.81$, QD Cronbach's $\alpha=.83$ ).

\section{Procedure:}

The study was conducted according to the principles of the Declaration of Helsinki. The data were collected from March 2017 research teams. All participants took part in the study on a voluntary basis and provided an informed consent. The procedure across almost all study sites was identical-participants completed the paper-and-pencil questionnaires, including a demographic (i.e., age, gender, nationality) questionnaire, with an approximate time of participation of $\mathbf{2 5}$ minutes. In general, participants were not compensated for their participation,

\section{Results:}

To examine which brain quadrant was dominant within the study sample, means and standard deviations were computed (see Table 5).

Table5: Means and Standard Deviations of the Brain Dominance Preferences

\begin{tabular}{cccc}
\hline Item order & Dimension & Mean & $\begin{array}{c}\text { Standard } \\
\text { Deviation }\end{array}$ \\
\hline 1 & QC & 4.74 & 3.235 \\
2 & QD & 4.17 & 3.378 \\
3 & QB & 3.95 & 2.887 \\
4 & QA & 3.65 & 2.621 \\
\hline
\end{tabular}

To examine whether brain dominance was associated with age $(17-21,22-26$, and $27+$ years of age), nationality (Saudi Arabian, Egyptian, and Algerian), and/or gender (males and females), a series of 3-way, between-group analyses of variance (ANOVAs), with brain quadrants as the dependent variables, and age, gender and nationality as the independent variables (see Table 6 for descriptive statistics). 
مجلة كلية التربية، جامعة الأزهر، العدد: (180، الجزء الثاني) أكتوبر لسنة 2018م

\begin{tabular}{|c|c|c|c|c|c|c|}
\hline \multicolumn{7}{|c|}{$\begin{array}{l}\text { Table 6: Means and Standard Deviations of Brain Dominance } \\
\text { Preferences Based on Gender, Age Group, and Citizenship }\end{array}$} \\
\hline Variable & & $\begin{array}{l}\text { Statisti } \\
\text { cs }\end{array}$ & $\mathbf{Q A}$ & QB & $\mathbf{Q C}$ & QD \\
\hline \multirow{4}{*}{ Gender } & \multirow[t]{2}{*}{$\mathbf{M}$} & M. & 3.58 & 3.78 & 4.47 & 3.89 \\
\hline & & SD & 2.547 & 2.739 & 3.034 & 3.147 \\
\hline & \multirow{2}{*}{$\mathbf{F}$} & $\mathbf{M}$ & 3.72 & 4.15 & 5.05 & 4.49 \\
\hline & & SD & 2.704 & 3.040 & 3.428 & 3.601 \\
\hline \multirow{6}{*}{ Age } & \multirow{2}{*}{ 17-21 } & $\mathbf{M}$ & 3.20 & 3.74 & 4.27 & 3.90 \\
\hline & & SD & 1.980 & 2.680 & 3.065 & 3.214 \\
\hline & \multirow{2}{*}{$22-26$} & $\mathbf{M}$ & 3.96 & 4.18 & 5.25 & 4.51 \\
\hline & & SD & 2.808 & 3.008 & 3.319 & 3.486 \\
\hline & \multirow{2}{*}{$27+$} & M & 3.20 & 3.55 & 3.81 & 3.50 \\
\hline & & SD & 2.500 & 2.695 & 2.891 & 3.119 \\
\hline \multirow{6}{*}{ Nationality } & \multirow{2}{*}{$\begin{array}{c}\text { Saudi } \\
\text { Arabian }\end{array}$} & $\mathbf{M}$ & 3.86 & 4.58 & 5.71 & 4.77 \\
\hline & & SD & 2.584 & 2.823 & 3.125 & 3.546 \\
\hline & \multirow{2}{*}{ Egyptian } & $\mathbf{M}$ & 2.48 & 2.50 & 2.43 & 2.33 \\
\hline & & SD & 2.003 & 2.119 & 1.868 & 1.922 \\
\hline & \multirow{2}{*}{ Algerian } & $\mathbf{M}$ & 4.57 & 4.70 & 5.94 & 5.34 \\
\hline & & SD & 2.784 & 3.096 & 3.234 & 3.567 \\
\hline
\end{tabular}


مجلة كلية التربية، جامعة الأزهر، العدد: (180، الجزء الثاني) أكتوبر لسنة 2018م

Table 7: Three-Way ANOVA Analysis of Gender, Age Group, and Citizenship Impact on Brain Dominance Preferences

\begin{tabular}{cccc}
\hline $\begin{array}{c}\text { Source of } \\
\text { variance }\end{array}$ & Dimension & F-Value & Significance \\
\hline \multirow{3}{*}{ Gender } & QA & .451 & .502 \\
& QB & 3.383 & .066 \\
& QC & 7.388 & .007 \\
Age & QD & 5.979 & .015 \\
\cline { 2 - 4 } & QA & .182 & .834 \\
& QB & .477 & .621 \\
QC & 1.315 & .269 \\
Nationality & QD & .681 & .507 \\
& QA & $\mathbf{2 9 . 9 1 9}$ & $<.001$ \\
& QB & 40.590 & $<.001$ \\
& QC & $\mathbf{8 8 . 0 3 2}$ & $<.001$ \\
& QD & 49.190 & $<.001$
\end{tabular}

This analysis demonstrated that women reported greater QC and QD dominance than men (see Table 7). No other significant differences were found for gender or age. Analyses also demonstrated significant between group differences in brain dominance as a function of nationality.

There are statistically significant differences $(\square=0.05)$ due to the effect of nationality in all fields, up to differences in English speech at King Abdulaziz University (table 8).

Table 8: Comparative comparisons in a descriptive manner to the effect of nationality

\begin{tabular}{|c|c|c|c|c|c|}
\hline Variable & & Mean & Saudi & Egyptian & Algerian \\
\hline \multirow{3}{*}{ QA } & Saudi & 3.86 & & & \\
\hline & Egyptian & 2.48 & $1.38 *$ & & \\
\hline & Algerian & 4.57 & $.71 *$ & 2.09* & \\
\hline \multirow[t]{2}{*}{ QB } & Saudi & 4.58 & & & \\
\hline & Egyptian & 2.50 & 2.08* & & \\
\hline
\end{tabular}


مجلة كلية التربية، جامعة الأزهر، العدد: (180، الجزء الثاني) أكتوبر لسنة 2018م

\begin{tabular}{|c|c|c|c|c|c|}
\hline \multicolumn{2}{|l|}{ Variable } & Mean & Saudi & Egyptian & Algerian \\
\hline & Algerian & 4.70 & .13 & $2.20 *$ & \\
\hline & Saudi & 5.71 & & & \\
\hline \multirow[t]{3}{*}{ QC } & Egyptian & 2.43 & $3.28 *$ & & \\
\hline & Algerian & 5.94 & .23 & $3.51 *$ & \\
\hline & Saudi & 4.77 & & & \\
\hline \multirow[t]{2}{*}{ QD } & Egyptian & 2.33 & $2.44 *$ & & \\
\hline & Algerian & 5.34 & .57 & 3.01* & \\
\hline
\end{tabular}

* Function at significance level $(\square=0.05)$.

Table (8) shows that differences were statistically significant $((\square=0.05)$ between Algerian on the one hand and Saudi and Egyptian on the other. Differences were in favor of the Algerian in QA. There were also differences of statistical significance $((\square=$ 0.05) between Egyptian on the one hand and Saudi and Algerian on the other. Differences were in favor of both Saudi and Algerian in QB, QC and QD.

To examine the relation between brain dominance and use of technology for learning purposes, Pearson correlation coefficients between the two measures were calculated (Table 9).

Table 9: Pearson Correlation Coefficients Between Brain Dominance and Use of Technology for Learning Purposes

\begin{tabular}{lccc}
\hline \multirow{2}{*}{$\begin{array}{c}\text { Brain Dominance } \\
\text { Preferences }\end{array}$} & $\begin{array}{c}\text { Statistics } \\
\text { Correlation } \\
\text { Coefficient }\end{array}$ & Significance & $N$ \\
\hline QA & $.124^{* *}$ & .002 & 634 \\
\hline QB & $.180^{* *}$ & $<.001$ & 634 \\
\hline QC & $.234^{* *}$ & $<.001$ & 634 \\
\hline QD & $.200 * *$ & $<.001$ & 634 \\
\hline$p<0.05, * * p<0.01$ & & &
\end{tabular}

All brain dominance preferences were significantly positively correlated with use of technology for learning purposes. 
Finally, to establish the extent with which brain dominance preferences uniquely predict the use of technology for learning purposes, a multiple regression analysis was conducted (Table 10). This analysis adjusts for the presence of other brain dominance variables, unlike the unadjusted Pearson correlations.

Table 10: Multiple Regression Analysis Predicting Use of Technology for Learning from Brain Dominance

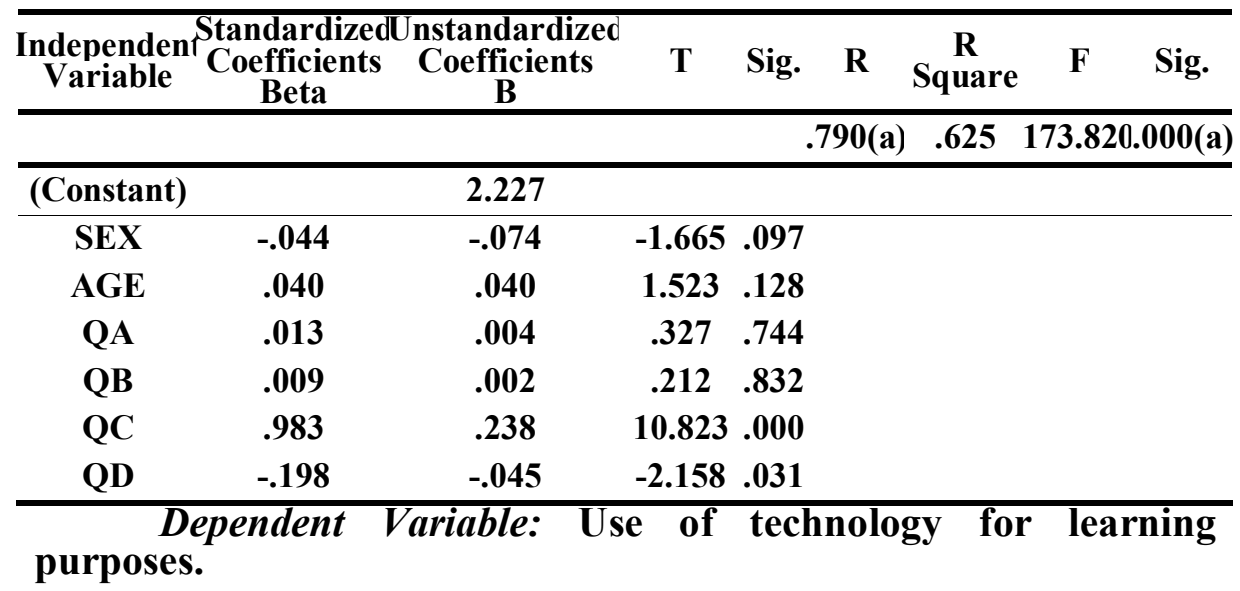

Table 10 displays that the brain dominance variables accounted for $79 \%$ of the variance in using technology for learning purposes. Adjusting for the other brain dominance predictor variables, only QC (positively) and QD (inversely) were significant.

\section{Discussion:}

The current study aimed to explore associations between brain dominance and the use of technology for learning purposes. Results demonstrated that women reported greater QC and QD dominance than men. Moreover, significance between group differences in brain dominance was demonstrated as a function of nationality. All brain dominance preferences were significantly positively correlated with the use of technology for learning purposes. The brain dominance variables accounted for $79 \%$ of the variance in using technology for learning purposes. However, when adjusting for the other brain dominance predictor variables, only QC (positively) and QD (inversely) were significant.

The possibility that children who grow up immersed in digital media think and learn differently from those who grew up with printed text has intuitive appeal, and research on neural plasticity has shown that our brains do indeed change in response to our repeated experiences (Ebner, 1996; Maguire,Woollett, \& 
Spiers, 2006). Since neural plasticity can lead to either adaptive or maladaptive changes (Nelson, 1999), these characteristics could manifest themselves in ways that are productive for learning, as suggested by Prensky (2001b, p. 442, 2001c), Rosen (2010), and Tapscott $(2009$, p. 368), or in ways that interfere with learning, as suggested by Bauerlein (2008), Carr (2010, p. 276), and Small and Vorgan (2008). Thus, the field of education needs more empirical study on whether and how technology immersion is associated with behaviors and attitudes related to learning.

Prensky $(2001 b$, p. 442, 2001c) claims that the intensity with which many young people play video games and use other digital technology results in exactly the kind of training that can profoundly affect the development of their young, highly plastic brains, resulting in superior visual skills, hand-eye coordination, and ability to monitor multiple processes and react quickly to unexpected events. Small and Vorgan (2008) also discuss the effects of digital immersion on young, highly plastic brains, but caution that it may be overdeveloping certain regions of the brain while neglecting others. In particular, they are concerned that gaming and other digital activities appear to suppress activity in the frontal lobe, the brain region responsible for planning, abstract thinking, and perspective-taking. They fear that the hours spent on the computer instead of reading books might be developing the temporal lobe at the expense of the frontal lobe, leaving a generation of students unable to think deeply and reflectively, control impulses, or feel empathy for others.

Smith (2011) points out that neural plasticity is involved in all learning, not just learning from technology, and studies (e.g., Maguire et al., 2006) demonstrate that measureable physical brain change also occurs in adult learners. While brain science research has demonstrated specific and rapid changes unique to adolescence, the direct link between observable physical brain change and adolescent behavior is not yet clear (Blakemore \& Choudhury, 2006; Giedd, 2004; Steinberg, 2005). Thus, while many of the popular press authors rely heavily on neural plasticity as a basis for their claims, academic researchers caution that our knowledge of neural plasticity alone is not enough to explain learning or to support prescriptive advice for teaching (Bruer, 1998). Despite the possible over-extension of the concept of neural plasticity and its implications for the digital native generation, however, the undoubted existence of neural plasticity is a reason for concern that immersion in digital technology from a young age could alter brain structure.

The preference of using $Q C$ and $Q D$, which represent the right hemisphere, may be attributed to one hemisphere of the brain having more activity than the other. What makes an 
individual dependent on one hemisphere more than the other? Preference is expected to depend on the nature of the activity or the task (Nishizawa, 1994; Alghraibeh, 2015). Most creative and artistic activities require activation of the right hemisphere. The right hemisphere is responsible for functions associated with intuition, emotion, creativity, imagination, and response to emotional stimuli, hence it is called the sensory, emotional, or intuitive hemisphere (Annett, 1998). It is the hemisphere that exhibits increased facial recognition, due to constant contact with the amygdala through neuronal connections that function to inhibit emotional responding and facilitate context- appropriate responses (Temple, 2002).

The differences in QC and QD in favor of females may be attributed to the emotional brain of the right hemisphere (Goleman, Boyatzis, \& McKee, 2013). Bruck (1979) defined certain functions for the right brain, such as responsibility for processing emotions (e.g., laughter and tolerance)." The left frontal lobe represents positive emotional responses, but the right frontal lobe is associated with negative emotional responses (Wheeler, Davidson, \& Tomarken, 1993). The brain is physically different between males and females. In a study which presented a set of pictures to participants and asked them to explain the emotions they saw in the pictures, males noticed key indicators of emotions, while females recognized precise indicators, and were able to more accurately determine the correct emotions compared with males, but it took them longer to do so (Wang, 2008). Additionally, corpus callosum volume tends to be greater among females, appearing more developed compared to males, resulting in pulses traveling between neurons of the hemispheres 5-10\% faster. Furthermore, the corpus callosum reaches its maturity three years earlier in females than in males (Herrmann, 1995). This suggests that many females are able to transfer a higher volume of data (ideas) at a faster rate than males.

The differences in QB, QC, and QD preferences in favor of the Saudi Arabian and Algerian nationalities, and the differences in the QA preferences in favor of the Algerian nationality may be attributed to differences in curriculum construction, and the cognitive abilities included therein. In addition, there may exist differences in teaching techniques among the nationalities, such as activity presentation (e.g., dialogue/story telling), which may ultimately affect brain dominance preferences (Kovalik, 2002). Brain preferences are associated with efficacy, because individuals tend to expend effort on what they most prefer. To achieve worldclass levels or high performance in any domain is impossible unless it is a basic preference domain (Herrmann \& HerrmannNehdi, 2015). Important life events, crises, major job changes, and 
important learning experiences may alter brain dominance (Herrmann, 1995). This result may also be attributed to expectations and social trends (Thomas \& French, 1985). After all, societal attitudes and culture affect the content and importance of needs required by individuals, through the dictations and role determination of the society (Jensen, 1998). Natural differences among individuals may reveal a cultural bias. For example, individuals from some parts of the U.S. (California) and India exhibit preferences for $\mathrm{QC}$ and $\mathrm{QD}$, while individuals from other parts of the U.S. (Ohio) and Germany exhibit preferences for QA and $Q B$. The meaning of having one basic preference is that the individual proceeds living with few internal contradictions, and his/her perception and decision-making processes tend to be homogeneous and predictable (Herrmann, 1991).

Additionally, this type of research can help in curriculum design and planning, and to facilitate the construction of training programs for teachers, helping them to acquire the ability to teach effectively through technology, and to develop new assessment methods that agree with the use of such technology.

\section{Study Limitations:}

Generalizing the findings of the study might be confined by the following: The sample only included three age groups; therefore, more age groups should be examined. Findings may also not be generalizable to other nationalities or populations, especially considering that populations may differ in their access to technology, as well as have different learning experiences that could influence brain dominance. Finally, brain dominance was assessed through self-report. Future studies would benefit from more objective measures of brain dominance, including the use of fMRI technology.

Recommendations for Future Research: There are many possible research topics that need to be recommended in this research. Conducting more research to identify the reasons for differences in brain dominance between males and females and conducting more research on brain dominance and the use of technology for learning purposes in different age groups are very crucial when dealing with this topic. Also important is exploring the correlation between brain dominance and technology usage for learning purposes in other populations, revising curriculum design to make it more flexible and more appropriate for the developed digital technology and exploring cooperation mechanisms between psychologists, neurologists, curriculum designers, and computer programmers to develop more flexible programs that enable learning using technology. 
Compliance with Ethical Standards:

Ethical approval: All procedures performed in studies involving human participants were in accordance with the ethical standards of the institutional and/or national research committee and with the 1964 Helsinki declaration and its later amendments or comparable ethical standards.

Informed consent: Informed consent was obtained from all individual participants included in the study. 


\section{References:}

Al Ghraibeh, A. and Al-Zahrani, A. (2013) Learning and Thinking Styles Based on Whole Brain Theory in Relation to Sensory-Motor Integration. Research in Neuroscience, 2, 1-10

Al Ghraibeh, A. M. A., \& Al-Zahrani, A. A. (2013). Learning and Thinking Styles Based on Whole Brain Theory in Relation to Sensory-Motor Integration. Research in Neuroscience, 2(1), 1-10. doi:10.5923/j.neuroscience.20130201.01

AlGhraibeh, A. M. A. (2015). Learning and thinking styles based on whole brain theory in relation to emotional intelligence. Open Access Library Journal, 2(5), 1. doi: 0.4236/oalib.1101436

Al-Nawafleh, W. (2008). The effect of learning styles and the corresponding teaching methods on the academic immediate and delayed achievement in chemistry of the 9th grade students (Unpublished doctoral dissertation). Yarmouk University, Irbid, Jordan.

Anderson, M. (2010). A more cerebral cortex. IEEE Spectrum, 47(1). doi: 10.1109/MSPEC.2010.5372504

Annett, M. (1998). Language, speech and cerebral dominance. Cahiers de Psychologie Cognitive/Current Psychology of Cognition, 17(6), 1118-1125.

Baird, D. E., \& Fisher, M. (2005). Neomillennial user experience design strategies: Utilizing social networking media to support "always on" learning styles. Journal of Educational Technology Systems, 34(1), 5-32. doi:10.2190/6WMW-47L0M81Q-12G1

Boekaerts, M., \& Minnaert, A. (2006). Affective and motivational outcomes of working in collaborative groups. Educational Psychology, 26(2), 187-208. doi:10.1080/01443410500344217

Bruck, K. (1979). Introduction to human anatomy. New York: Harper \& Row.

Champeau, R. (2008). UCLA study finds that searching the Internet increases brain function. UCLA Newsroom, 14.

Christof van Nimwegen. (2003). "Externalization vs. Internalization: The influence on problem solving performance." Institute of Information and Computing Sciences, Utrecht University Padualaan. 14, $3584 \mathrm{CH}$ Utrecth, The Netherlands. 2003 
مجلة كلية التربية، جامعة الأزهر، العدد: (180، الجزء الثاني) أكتوبر لسنة 2018م

Cicchetti, D. (2016). Developmental psychopathology, maladaptation and psychopathology (Vol. 3). Hoboken: John Wiley \& Sons.

Cicconi, M. (2014). Vygotsky meets technology: A reinvention of collaboration in the early childhood mathematics classroom. Early Childhood Education Journal, 42(1), 57-65. doi.org/10.1007/s10643-013-0582-9

Craver, B. D. (2014). [Review of the book Five big ideas for effective teaching: Connecting mind, brain, and education research to classroom practice, by $D$. Wilson \& M. Conyers]. Teaching Theology \& Religion, 17(2), 181-182.

Creswell, J. (2007). Educational Research: Planning, Conducting, and Evaluating Quantitative and Qualitative Research. Upper Saddle River, NJ: Pearson.

Davi, A., Frydenberg, M., \& Gulati, G. J. (2007). Blogging across the disciplines: Integrating technology to enhance liberal learning. Journal of Online Learning and Teaching, 3(3).

De Boer, A. L. (1999). Thinking style preferences of underprepared first year students in the natural sciences. South African Journal of Ethnology, 22(3), 97-102.

De Boer, A. L., \& Van den Berg, D. (2001). The value of the Herrmann Brain Dominance Instrument (HBDI) in facilitating effective teaching and learning of Criminology. Acta Criminologica, 14(1), 111-121.

Decety, J. (2011). The neuroevolution of empathy. Annals of the New York Academy of Sciences, 1231(1), 35-45.

Dell, A. G., Newton, D. A., \& Petroff, J. G. (2016). Assistive technology in the classroom: Enhancing the school experiences of students with disabilities. London: Pearson.

Dickey, M. (2004). The impact of web-logs (blogs) on student perceptions of isolation and alienation in a web-based distance-learning environment. Open Learning, 19(3), 279291. doi:10.1080/0268051042000280138

Doerfel, M. L., \& Moore, P. J. (2016). Digitizing strength of weak ties: Understanding social network relationships through online discourse analysis. Annals of the International Communication Association, 40(1), 127-148.doi: 10.1002/j.2162-6057.1991.tb01140.x

Driscoll, M., \& Driscoll, M. (2005). Psychology of learning for instruction. Boston, MA: Allyn \& Bacon. 
Eagle, N., Pentland, A. S., \& Lazer, D. (2009). Inferring friendship network structure by using mobile phone data. Proceedings of the National Academy of Sciences, 106(36), 15274-15278.

Fanning, C. (1983). A study of the relative effectiveness of reading level, IQ, sex, handedness and hemispheric preference in the prediction of reading achievement (Doctoral dissertation). Retrieved from ProQuest Dissertations \& Theses (Publication number 8321257).

Florey, J. (1985). Modification in styles of learning and thinking (hemisphericity) through direct training of sixth grade students (cerebral preference, dominance) (Doctoral dissertation). Retrieved from ProQuest Dissertations \& Theses (Publication number 8510993).

Fountain, J. (1986). The relationship among hemispheric brain preference, gender, and academic achievement of fourth and seventh grade pupils (Doctoral dissertation). Retrieved from ProQuest Dissertations \& Theses (Publication number 8715993).

Fountain, J. C. (1986). The relationship among hemispheric brain preference, gender, and academic achievement of fourth and seventh grade pupils (Doctoral dissertation, University of Florida).

Garfinkel, S. N., \& Critchley, H. D. (2013). Interoception, emotion and brain: New insights link internal physiology to social behaviour. Commentary on: "Anterior insular cortex mediates bodily sensibility and social anxiety" by Terasawa et al. (2012). Social Cognitive and Affective Neuroscience, 8(3), 231-234.

Goleman, D. (2000) Emotional Intelligence Trans. Laila Al-Jabali, Knowledge World, Kuwait.

Goleman, D., Boyatzis, R. E., \& McKee, A. (2013). Primal leadership: Unleashing the power of emotional intelligence. Cambridge, MA: Harvard Business Press.

Goorha, P., \& Mohan, V. (2009). Understanding learning preferences in the business school curriculum. Journal of Education for Business, 85(3), 145-152. doi:10.1080/08832320903252363

Hauck, L. (1985). Differences in information mapping strategies in left and right brain learners (Doctoral dissertation). Retrieved from ProQuest Dissertations \& Theses (Publication number 8516030). 
Herrmann, N. (1991). The creative brain. The Journal of Creative Behavior, 25(4), 275-295.

Herrmann, N. (1995) The Creative Brain. Quebecor Printing Book, USA.

Herrmann, N. (1995). The creative brain (2nd ed). Lake Lure, NC: Ned Herrmann Group.

Herrmann, N., \& Herrmann-Nehdi, A. (2015). The whole brain business book: Unlocking the power of whole brain thinking in organizations, teams, and individuals. New York: McGraw Hill Professional.

Jensen, E. (1998). Teaching with the brain in mind. Alexandria, VA: ASCD.

Kathleen, B., \& Eliassen, J. (1998). Modular organization of cognitive system masked by interhemispheric integration. Science, 280(5), 902-906.

Kennedy, G., Dalgarno, B., Gray, K., Judd, T., Waycott, J., Bennett, ... Churchwood, A. (2007). The net generation are not big users of Web 2.0 technologies: Preliminary findings. In R. Atkinson, C. Mcbeath, A. Soong Swee Kit, \& C. Cheers (Eds.), Annual Conference of the Australasian Society for Computers in Learning in Tertiary Education (pp. 517-252). Singapore: Nanyang Technology University.

Kerawalla, L., Minocha, S., Kirkup, G., \& Conole, G. (2008). Characterising the different blogging behaviours of students on an online distance learning course. Learning, Media and Technology, 33(1), 21-33.

Kirkwood, A., \& Price, L. (2014). Technology-enhanced learning and teaching in higher education: What is "enhanced" and how do we know? A critical literature review. Learning, Media and Technology, 39(1), 6-36, 331-349.

Klopfer, E., Osterweil, S., Groff, J., \& Haas, J. (2009). Using the technology of today in the classroom today: The instructional power of digital games, social networking, simulations and how teachers can leverage them. The Education Arcade, 1, 20.

Kovalik, S., \& Olsen, K. (2002). Exceeding expectations: A user's guide to implementing brain research in the classroom. Federal Way, WA: Susan Kovalik \& Associates. 
Kunisato, Y., Okamoto, Y., Okada, G., Aoyama, S., Nishiyama, Y., Onoda, K., \& Yamawaki, S. (2011). Personality traits and the amplitude of spontaneous low-frequency oscillations during resting state. Neuroscience Letters, 492(2), 109-113. doi:10.1016/j.neulet.2011.01.067

Lahnakoski, J. M., Glerean, E., Salmi, J., Jääskeläinen, I. P., Sams, M., Hari, R., \& Nummenmaa, L. (2012). Naturalistic FMRI mapping reveals superior temporal sulcus as the hub for the distributed brain network for social perception. Frontiers in Human Neuroscience, 6, 233. doi:10.3389/fnhum.2012.00233

Lamm, C., \& Singer, T. (2010). The role of anterior insular cortex in social emotions. Brain Structure and Function, 214(5-6), 579-591.

Laurillard, D. (2013). Rethinking University Teaching: A conversational framework for the effective use of learning technologies. London: Routledge.

Li, W., Mai, X., \& Liu, C. (2014). The default mode network and social understanding of others: What do brain connectivity studies tell us? Frontiers in Human Neuroscience, 8, 74. DOI.10.3389/fnhum.2014.00074

Lieberman, M.D. (2012). Education and the social brain. Trends in Neuroscience and Education (1) 3-9

Liu, T., \& Graf, S. (2009). Coping with mismatched courses: students' behaviour and performance in courses mismatched to their learning styles. Educational Technology Research and Development, 57(6), 739-752. doi:10.1007/s11423-0099116-y

Luh, S. (1990). A study of learning styles, personality types, and brain hemispheric preferences of teacher education majors(Doctoral dissertation). Retrieved from ProQuest Dissertations \& Theses (Publication number 9104024).

Ma, Y., Wang, C., Li, B., Zhang, W., Rao, Y., \& Han, S. (2013). Does self-construal predict activity in the social brain network? A genetic moderation effect. Social Cognitive and Affective Neuroscience, 9(1), 1360-1367. doi:10.1093/scan/nst125

MacLean, P. D. (1978). A mind of three minds: Educating the triune brain. Chicago: National Society for the Study of Education. 
Mikkelson, A. C., Farinelli, L., \& La Valley, A. G. (2006). The influences of brain dominance and biological sex on emotional expressivity, sensitivity, and control. Communication Quarterly, 54(4), 427-446. doi:10.1080/01463370601035947

Miller, G. (2011). The brain's social network. Science, 334(6056), 578-579. doi:10.1126/science.334.6056.578

Minotti, J. (2009). Effects of learning-style-based homework prescriptions on the achievement and attitudes of middle school students. NASSP Bulletin, 89 (642): 67-89. Retrieved 06.04.2015, From SAGEpub Masterfile Database.

Minotti, J. L. (2005). Effects of learning-style-based homework prescriptions on the achievement and attitudes of middle school students. NASSP Bulletin, 89(642), 67-89. doi:10.1177/019263650508964206

Nishizawa, S. (1994). Cross-cultural effects on hemispheric specialization reflected on a task requiring spatial discrimination of the thumb by Japanese and American students. Perceptual and Motor Skills, 78(3), 771-776. doi:10.2466/pms.1994.78.3.771

O'Gorman, R., Kumari, V., Williams, S., Zelaya, F., Connor, S., Alsop, D., \& Gray, J. (2006). Personality factors correlate with regional cerebral perfusion. Neuroimage, 31(2), 489495. doi:10.1016/j.neuroimage.2005.12.048

Ohler, J. (2008). The semantic web in education. Educause Quarterly, 31(4), 7-9.

Orlich, D. C., Harder, R. J., Trevisan, M. S., Brown, A. H., \& Miller, D. E. (2016). Teaching strategies: A guide to effective instruction. Boston: Cengage Learning.

Penfield, W., \& Roberts, L. (2014). Speech and brain mechanisms. Princeton, NJ: Princeton University Press.

Rahimi, E., Berg, J., \& Veen, W. (2015). A learning model for enhancing the student's control in educational process using Web 2.0 personal learning environments. British Journal of Educational Technology, 46(4), 780-792.

Rajput, J. R., Deshpande, P. M., \& Wadhekar, A. R. (2015). Brain fingerprinting technology. International Journal Of Engineering Research and Applications, 5(1), 99-104. 
Roalf, D. R., Ruparel, K., Gur, R. E., Bilker, W., Gerraty, R., Elliott, M. A., ... \& Wood, J. (2014). Neuroimaging predictors of cognitive performance across a standardized neurocognitive battery. Neuropsychology, 28(2), 161.

Rodriguez, I., \& Rafael, N (1994). Hemisphere's Mode of Cognitive Function in a Finnish School: Grades and Behavior. Educational Psychology, 14(2): 207-217.

Salmons, J. (2009). E-social constructivism and collaborative elearning. In J. Salmons \& L. Wilson (Eds.), Handbook of research on electronic collaboration and organizational synergy (pp. 280-294). Hershey, PA: Information Science Reference.

Sato, W., Toichi, M., Uono, S., \& Kochiyama, T. (2012). Impaired social brain network for processing dynamic facial expressions in autism spectrum disorders. BMC Neuroscience, 13(1), 2-17 doi:10.1186/1471-2202-13-99

Schlesinger, J. (1985) Hemisphericity, Field Dependence Independence, and Preference for Musical Improvisation:Relationships among Cognitive and Musical Styles. Proquest Dissertation, New York University, New York, 135B(AAT NO. 8521989).

Shaw, K., Brennan, N., Woo, K., Zhang, Z., Young, R., Peck, K. K., \& Holodny, A. (2016). Infiltration of the basal ganglia by brain tumors is associated with the development of codominant language function on fMRI. Brain and Language, $155,44-48$.

She, H. (2005). Promoting students' learning of air pressure concepts: The interrelationship of teaching approaches and student learning characteristics. The Journal of Experimental Education, 74(1), 29-52.

Shelnutt, J., Middleton, S., Buch, K., \& Lumsdain, M. (1996, May). Forming student project teams based on Herrmann Brain Dominance (HBDI) results. Paper presented at the ASEE Annual Conference, Evanston, IL.

Siemens, G. (2005). Connectivism: A learning theory for the digital age. International Journal of Instructional Technology \& Distance Learning, 2(1).

Slack, N., \& Norwich, B. (2007). Evaluating the reliability and validity of a learning styles inventory: A classroom-based study. Educational Research, 49(1), 51-63. doi:10.1080/00131880701200765 
مجلة كلية التربية، جامعة الأزهر، العدد: (180، الجزء الثاني) أكتوبر لسنة 2018م

Soliman, A. (1989). Sex differences in the styles of thinking of college students in Kuwait. Journal of Creative Behavior, 23(1), 38-45. doi:10.1002/j.2162-6057.1989.tb00516.x

Springer S., \& Deutsch, G. (1999). Left brain, right brain: Perspectives From Cognitive Neurosciences. New York: Freeman \& Company.

Starkey, L. (2011). Evaluating learning in the 21st century: A digital age learning matrix. Technology, Pedagogy and Education, 20(1), 19-39.

Temple, C. (2002). The brain: An introduction to the psychology of the human brain and behavior. Penguin Books, UK.

Thomas, J., \& French, K. (1985). Gender differences across age in motor performance: A meta-analysis. Psychological Bulletin, 98(2), 260-282. doi:10.1037/0033-2909.98.2.260

Thompson, D. K., Lee, K. J., van Bijnen, L., Leemans, A., Pascoe, L., Scratch, S. E., ... \& Anderson, P. J. (2015). Accelerated corpus callosum development in prematurity predicts improved outcome. Human Brain Mapping, 36(10), 37333748.

Tochi Iroku-Malize .(2015) Two Views: Technology for Learning: INNOVATIVE TECHNOLOGY • Family Doctor • A Journal of the New York State Academy of Family Physicians. Volume three Number four, 10-15

Tokuhama-Espinosa, T. (2015). The new science of teaching and learning: Using the best of mind, brain, and education science in the classroom. New York: Teachers College Press.

Van Harmelen, M. (2008). Design trajectories: Four experiments in PLE implementation. Interactive Learning Environments, 16(1), 35-46. doi:10.1080/10494820701772686.

Von Der Heide, R., Vyas, G., \& Olson, I. R. (2014). The social network-network: Size is predicted by brain structure and function in the amygdala and paralimbic regions. Social Cognitive and Affective Neuroscience, 9(12), 1962-1972. doi:10.1093/scan/nsu009.

Wang, C. (2008). Gender differences in responding to sad emotional appeal: A moderated mediation explanation. Journal of Nonprofit \& Public Sector Marketing, 19(1), 55-70. doi:10.1300/J054v19n01_03.

Webb, W., \& Adler, R. K. (2016). Neurology for the speechlanguage pathologist. Elsevier Health Sciences. 
Wei, L., Duan, X., Yang, Y., Liao, W., Gao, Q., Ding, J., ... \& Chen, H. (2011). The synchronization of spontaneous BOLD activity predicts extraversion and neuroticism. Brain Research, 1419, 68-75. doi:10.1016/j.brainres.2011.08.060

West, R., Wright, G., Gabbitas, B., \& Graham, C. (2006). Reflections from the introduction of blogs and RSS feeds into a preservice instructional technology course. TechTrends, 50(4), 54-60. doi:10.1007/s11528-006-0054-9

Wheeler, R., Davidson, R., \& Tomarken, A. J. (1993). Frontal brain asymmetry and emotional reactivity: A biological substrate of affective style. Psychophysiology, 30(1), 82-89. doi:10.1111/j.1469-8986.1993.tb03207.x

Woo, Y., \& Reeves, T. (2007). Meaningful interaction in webbased learning: A social constructivist interpretation. The Internet and Higher Education, 10(1), 15-25. doi:10.1016/j.iheduc.2006.10.005

Wu, S., \& Alrabah, S. (2009). A cross $\square$ cultural study of Taiwanese and Kuwaiti EFL students' learning styles and multiple intelligences. Innovations in Education and Teaching International, 46(4), 393-403. doi:10.1080/14703290903301826

Yrttiaho, S., Forssman, L., Kaatiala, J., \& Leppänen, J. (2014). Developmental precursors of social brain networks: The emergence of attentional and cortical sensitivity to facial expressions in 5 to 7 months old infants. Developmental Precursors of Social Brain Networks, 9(6), 1-10. doi:10.1371/journal.pone.0100811 